sisting of equal numbers of positive and negative items.

We respect the criticism that some positive items (and indeed some negative items) were "qualified" and "hardly encouraging," but we considered only three of the statements to be qualified in the manner suggested by Dr Turner. These qualified statements were partly to avoid implanting our own positive views on respondents and partly to convey different or clarified meaning to receptive patients. To use Dr Turner's example: "If computers mean less time in the waiting room they are a good thing" is essentially different in meaning from: "Computers will save time in the waiting room." The former seemed to us to be more appropriate as it demands no technical knowledge of the uses or capabilities of computers in the surgery, but seeks an opinion. Although there was strong agreement $(92 \%)$ only $1 \%$ of patients felt unable to respond to the item, which we took to be a measure of some success.

A direct comparison between the unqualified positive statement: "Computers could save money for the health service" and the qualified: "Even if doctors use computers they will see you for as long as before" showed respectively $\mathbf{7 7 . 5} \%$ agreement and $3 \%$ failure to respond, compared with $76 \%$ and $2 \%$. This does not suggest that qualification of positive statements is intrinsically likely to influence results.

We do not know of a perfect questionnaire and do not claim to have devised one, but we endeavour to maintain that the one used in our study was balanced and unbiased.

Michael Pringle

SALLY ROBINS

Health Centre,
Collingham,

Newark, Nott

Nottingham University

GEORGE BRown

Nottingham

\section{A romp around the United Kingdom} research centres

SIR,-Richard Wakeford and Robin Adams (28 January, $\mathrm{p} 297$ ) state in their discussion: "In interpreting the data, it should be noted also that Westminster Medical School is, uniquely, only a clinical school." During the period under survey (1973-81) King's College Hospital Medical School, also a solely clinical school, was in existence. Since 1 October 1983 we have been reunified with King's College London and now have the title King's College School of Medicine and Dentistry, incorporating the preclinical departments at the Strand.

King's College School of
Medicine and Dentistry,
London SE5 8RX

\section{J BRitTen} Secretary Medicine and $\mathrm{D}$

SIR,-As defined by the Oxford English Dictionary a romp has two components: one quantitative, but never measured, the other qualitative, and lively with it. As defined by Richard Wakeford and Robin Adams of Cambridge (28 January, p 297) a romp has but one component, quantitative; and how measured it is.

In search of quality, justifiably but sadly lacking in Cambridge romps, I perused other pages of that issue of the $B M \mathcal{H}$. Where better to find quality than in leading articles ? There not half a dozen lines into the first leading article, appeared the word "Cambridge," which-surprise-ranks first in joyless romps.

The same leading article clearly indicated that the fenland town had been merely the venue for a symposium on opioids to celebrate the 80th birthday of Professor Hans Kosterlitz. It was presumptively a halo effect, which obscured the fact that the work being praised and appraised originated largely in Aberdeen, which, like Leicester, indeed like all other medical schools of the United Kingdom, romps (Cambridge definition) home behind Cambridge when joyous quality is ignored.

How inviting of you to head the peccan article "For Debate. ..." The "never mind the quality, feel the width" approach, derived from the rag trade, should be consigned to the rag bag. The quality implicit in research romps (Oxford definition) may be best explored in your pages in a series akin to "Reading for Pleasure."

Department of Pathology,
University of Leicester,

F WALKER

Leicester LE2 7LX

\section{Muscle spasms associated with Sudeck's} atrophy after injury

SIR, - I was interested in the detailed electro physiology carried out in one of the patients described by Professor C D Marsden and others (21 January, p 173). I do not think, however, that it can be assumed that the reduc tion in jerks after intravenous local anaesthesia uis due to the peripheral effects of the lignocaine injected.

Professor Marsden and colleagues induced anaesthesia of the hand by injecting $5 \mathrm{ml}$ of $1 \%$ lignocaine $(50 \mathrm{mg})$ distal to a sphygmomanometer cuff inflated to $100 \mathrm{~mm} \mathrm{Hg}$ around the wrist. As it is relatively difficult to occlude the blood vessels lying in the forearm ${ }^{1}$ it seems unlikely that a cuff pressure of only $100 \mathrm{~mm}$ $\mathrm{Hg}$ would be adequate to prevent some of the lignocaine from escaping to the genera circulation. In the standard Bier's block technique, it is usual to inflate a cuff around the upper arm to $250-300 \mathrm{~mm} \mathrm{Hg}$, and even then leakage may occur across the cuff.'

There remains a possibility, therefore, that enough lignocaine leaked out to suppress direct a rhythmic focus of activity in the central nervous system. The fact that anticonvulsants were not effective is interesting but does not preclude this possibility.

If the opportunity arose again, it would be interesting to repeat this experiment using a wrist block rather than the intravenous technique described.

\section{Department of Anaesthesia Whipps Cross Hospital, condon E11 1NR \\ Weddell (;, Sinclair DC. "Pins and needles"- observations on some of the sensations aroused in Neuro Neurosurg Psychiatry $1947 ; 10: 26-46$ \\ Rosenberg PH, Kalso EA, Iuominen MK, Linden $\mathrm{HB}$. Acute bupivacaine toxicity as a result of venous eakage under the tourniquet cuff during a Bie}

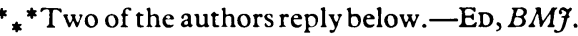

SIR,-We thank Dr Jessop for her comments on our report. The same effect on hand and finger movements in case 1 was obtained by anaesthesia achieved by inflating a sphygmomanometer cuff above arterial pressure for over an hour, so we believed that this action was peripheral.

C D MARSDEN J C ROTHWELI

Institute of Psychiatry,

London SE5 8AF

\section{Falciparum malaria resistant to} chloroquine and Fansidar: implications for prophylaxis

SiR,-Dr C Herzog and others (1 October, $p$ 947) draw attention to the increasingly difficult problem of malaria prophylaxis in east Africa. I wish to report a case that might have implications for the treatment of those returning from east Africa with severe falciparum malaria.

A 50 year old Marakwet woman with a long history of grand mal epilepsy, which had been quiescent for the past three years, presented with a history of four fits in the 24 hours before admission. She was taking no anticonvulsant medication. On examination she was drowsy and having leftsided focal fits of short duration. She had no neck stiffness, and lumbar puncture showed no abnormality. A thick film for malaria was found to contain numerous parasites and treatment with quinine and chloroquine was started. Fansidar was added on days three to five as there was no clinical improvement and the thick malaria slide continued to contain abundant parasites. On day seven she was continuing to have fits despite treatment with phenytoin, phenobarbitone, and diazepam. Her malaria thin film still contained $2 \%$ parasitaemia and tetracycline was added. Unfortunately the patient succumbed to an aspiration pneumonia on day nine, having had no improvement in her conscious level.

The practice in south east Asia would now be to offer combined quinine and tetracycline as initial treatment for severe infections ${ }^{1}$; this is not yet a requirement in east Africa. It now seems probable, however, with increasing evidence of Fansidar resistance, the apparently poor response to quinine in this case, and the slow response in the case reported by $\mathrm{Dr}$ Herzog and others, that such a combination should be seriously considered as the first line of treatment in severe falciparum malaria acquired in east Africa.

Incidentally, the woman described contracted her disease at an altitude of $2286 \mathrm{~m}$ $(7500 \mathrm{ft})$. Until recently this has been regarded by many as an environment relatively free from the risk of malaria.

SiMON J EYRE

\section{Kapsowar Hospital,}

Eldoret, Kenya

Reecher M, Campbell CC, Freeman J, Dobenstyn EB, Brandling-Bennett AD. Drug therapy for Plasmodium falciparum malaria resistant to pyrimethamine-sulfadoxine (Fansidar): a study of alternate regimen in Eastern Thailand 1980. Lancet 1981 ;i:1066-8.

\section{Excretion of verapamil in human milk}

SIR,-Dr H Inoue and others (26 November, p 1596) reported the maximum breast milk concentration of verapamil to be $300 \mathrm{ng} / \mathrm{l}$ in a mother receiving $320 \mathrm{mg}$ verapamil a daysay $4.6 \mathrm{mg} / \mathrm{kg} / 24$ hours for a $70 \mathrm{~kg}$ patient. 
Breast fed babies take about $150 \mathrm{ml} / \mathrm{kg}$ of milk in 24 hours. ${ }^{1}$ Therefore in the case quoted the baby's intake of verapamil would have been $45 \mathrm{ng} / \mathrm{kg} / 24$ hours, about $1 / 100000$ of the maternal dose. I therefore disagree with the authors' conclusion that women receiving verapanil should not breast feed.

M DE SWIET

Cardiothoracic Unit,
British Postgraduate Medical
Federation,
London SW3 6HP
' Illingworth RS. Common symptoms of disease in children.
6th ed. Oxford: Blackwell Scientific Publications,
1979:7.

**Dr Inoue replies below.-ED, $B M \Im$.

SIR,-The correct value of verapamil in maternal milk is $300 \mathrm{ng} / \mathrm{ml}$, not $300 \mathrm{ng} / \mathrm{l}$ as printed.

Provided that the baby takes $150 \mathrm{ml} / \mathrm{kg}$ of breast milk in 24 hours, the baby's intake of verapamil would be $45000 \mathrm{ng} / \mathrm{kg} / 24$ hoursthat is, $0.045 \mathrm{mg} / \mathrm{kg} / 24$ hours. This dose is about one hundredth of the maternal dose ( $4.6 \mathrm{mg} / \mathrm{kg} / 24$ hours). In a recently published case report serum concentration of verapamil in the child was $2 \cdot 1 \mathrm{ng} / \mathrm{ml}$ when verapamil concentration in mother's milk was about $30 \mathrm{ng} / \mathrm{ml} .^{1}$ Thus in our baby serum concentration of verapamil would be as high as $20 \mathrm{ng} / \mathrm{ml}$ if our baby took mother's milk.

It seems unclear whether verapamil at a serum concentration of $20 \mathrm{ng} / \mathrm{ml}$ is safe for a baby. In animal studies Shigenobu et al showed that young hearts were more susceptible to verapamil than older hearts. ${ }^{2}$ We believe, therefore, that women receiving verapamil should not breast feed until it is proved that this amount of verapamil is safe for the baby.

HiRoshi INOUE

\section{Second Department of Internal \\ Medicine, \\ University of Tokyo, \\ Tokyo, Japan}

Andersen HJ. Excretion of verapamil in human milk. Eur J Clin Pharmacol 1983;25:279-81

Shigenobu K, Schneider JA, Sperelakis $\mathrm{N}$. Verapamil
blockade of slow $\mathrm{Na}^{+}$and $\mathrm{Ca}^{++}$responses in myocardial cells. I Pharmacol Exp Ther 1974;190 280-8.

\section{Characteristics of patients aged over 75 not seen during one year in general practice}

SIR,-I would like to present the results of a study of elderly patients similar to that reported by Dr E Idris Williams (14 January, p 119).

Of the 15200 patients on the list of a large urban group practice in Keighley, West Yorkshire, $6 \%$ (912) were aged over 75 and $1.5 \%$ (223) were born before 1900 . The notes of all those born before 1900 were examined: $128(57 \%)$ had seen their general practitioner within the previous three months; $149(67 \%)$ within six months; $171(77 \%)$ within nine months; and $173(78 \%)$ within one year. The 52 patients who had not seen their general practitioner for more than nine months were selected for further study.

Of these, eight had died or were untraceable seven lived in part III or long stay geriatric hospital accommodation; and a further five requested a general practitioner visit during the study period (about eight weeks). As a general practitioner trainee I visited 25 of the remaining
32 patients in their homes (17 women and eight men). Using a standard questionnaire, I sought information about their home conditions, the support they required, their mobility, and their general health, including sight and hearing. A physical examination was performed, and 17 of the 25 agreed to have blood taken for full blood count, and estimation of erythrocyte sedimentation rate; urea, electrolytes, and sugar concentrations; and liver function and thyroid function.

The ages of those visited ranged from 83 to 92 years. On average it was two and a half years since they had seen a doctor, and only two had been seen during that time by a health visitor. The women were much more isolated than the men: $10(59 \%)$ of the women but none of the men lived alone; five $(62 \%)$ of the men but only two $(12 \%)$ of the women had a living spouse; on average women had been widowed for 20.2 years, men for 9.3 years; six of the women and none of the men had remained single.

Most of the patients could walk unaided both in and out of doors, and $20(80 \%)$ went out at least once a week. Most needed some help with shopping and cleaning but not with cooking. Eighteen $(72 \%)$ received regular visits from children, and $14(56 \%)$ from friends or neighbours - these were by far the most important groups of "carers." Only eight received any help at all from the social services. Sixteen $(64 \%)$ owned their own home, and all but two of the 25 homes were in reasonable condition.

Ten patients $(40 \%)$ took no regular medications, and none took more than three different medications. Eleven $(44 \%)$ had no complaints about their health; the commonest complaint was musculoskeletal pain (seven); a variety of other symptoms were reported, most of which were judged minor.

As a result of interviewing and examining the 25 patients two were referred regarding a hearing aid and three had their ears syringed; one was referred to the ophthalmology clinic; a chiropodist was arranged for one and a bath nurse for two. Two were judged to have early dementia and were referred for further assessment by the health visitor. One patient had treatment prescribed for a specific complaint.

Only two abnormalities of any note were found among the results of the blood tests: one case of iron deficiency anaemia requiring oral iron; and one of borderline primary hypothyroidism requiring follow up but not treatment.

The aim of the study was to assess how much unreported illness and need was being overlooked in elderly patients with no contact with primary health care services. Most of the patients visited seemed remarkably fit and were not suffering unduly as a result of their lack of medical attention. Over half the visits resulted in some action being initiated on the patient's behalf, however, and it was largely simple and remediable need rather than serious or complex disease that needed to be dealt with. This provides the main justification for performing such surveillance of the very elderly.

LES GOLdMAN

Ilkley,

SIR,-We have undertaken studies similar to that of Dr E Idris Williams in this practice, though our method of survey is different.

On a set occasion our secretaries scan the records of patients over 75; if there is no record of contact over the past year, we bring the records to a lunchtime meeting of the partners, district nurses, and health visitors. We then ascertain whether any of us have, in fact, had contact with the patient, either through a nursing visit, visiting someone else in the same house, a social contact, or even through knowing that they are still going to work. The remainder we follow up; in most cases a health visitor calls, but sometimes one of the partners calls, or we make a cheerful phone call.

Our figures for 1983 come out very similar to Dr Williams's. A total of $\mathbf{4 0 5}$ of our practice list of 9500 were aged over 75; of these 384 $(95 \%)$ had been seen in the previous year, had received a repeat prescription, or were known to be well. On follow up of the remaining 21,19 were reasonably well, but two needed continued care.

We first undertook this exercise some six years ago to see if there was a large group of elderly patients not in contact with us but in need. We were reasonably reassured by the result, but have felt the survey worth repeating every two years since. It has an additional value-it shows the practice team just how interdependent we are in sharing in the care of the elderly.

Coleshill,

J M STUART

Birmingham B46 3LD

\section{Prevention of urinary retention with phenoxybenzamine during epidural morphine}

SIR,-The paper by Dr Samuel Evron and others (21 January, p 190) reflects the growing interest in the clinical effects of opiate analgesics and their possible relation with the endogenous opioid peptidergic nervous system. Although the results suggest that $\alpha$ adrenergic blockade is useful in alleviating voiding problems after combined epidural anaesthesia and epidural morphine, several points are worthy of comment.

In general terms the opioid peptides are the active agents of an inhibitory control system (28 January, p 259). In relation to the lower urinary tract opiate analgesics decrease detrusor tone," while the potent specific opiate and opioid antagonist, naloxone, increases detrusor contractility, reduces functional bladder capacity, and may provoke detrusor instability. ${ }^{2}$ In addition, intrathecal morphine has been reported to abolish detrusor instability in patients with neurogenic bladder disturbance. ${ }^{3}$ All these factors point to a role for opioid peptidergic interaction in the autonomic control of the lower urinary tract, presumably via opiate receptors.

Enkephalinergic nerve fibres have been shown in the sacral autonomic nucleus (intermediolateral grey matter) of the cat, ${ }^{4}$ and a similar distribution is seen in the midsacral cord segments in man. These fibres and their associated receptors could allow for a direct central effect of spinal opiates on detrusor function.

Although $\alpha$ adrenergic innervation of the male bladder neck is well recognised and colleagues of Dr Evron and others at Hadassah have shown the efficacy of $\alpha$ blockade in acute urinary retention of prostatic origin ${ }^{5}$ it is dangerous to extrapolate to the female urethral closure mechanism, on which the evidence for $\alpha$ adrenergic innervation is inconclusive. A possible site of interaction, however, exists in the thoracic cord, where sympathetic preganglionic cell bodies have been described surrounded by terminals containing both enkephalins and substance P. ${ }^{\circ}$ Treatment with phenoxybenzamine may be useful in patients such as those described but probably does not attack the cause of the voiding difficulty, 